\title{
The Analgesic Effects of Thoracic Paravertebral Block versus Thoracic Epidural Anesthesia After Thoracoscopic Surgery: A Meta-Analysis
}

This article was published in the following Dove Press journal: Journal of Pain Research

\section{Xiao-Long Liang $(\mathbb{D}$ \\ Ran An \\ Qi Chen (iD) \\ Hong-Liang Liu}

Chongqing University Cancer Hospital, School of Medicine, Chongqing University, Chongqing, 400030, People's Republic of China
Correspondence: Hong-Liang Liu Chongqing University Cancer Hospital, School of Medicine, Chongqing University, No. I8I, Hanyu Road, Shapingba District, Chongqing, 400030, People's Republic of China

Tel +86 I388368672I

Email liuhl75@I63.com
Background: To date, there is no definitive evidence for the analgesic effects and side effects of thoracic epidural anesthesia (TEA) versus thoracic paravertebral block (TPVB) after thoracoscopic surgery. In this study, we conducted a meta-analysis of published randomized clinical trials (RCTs) to analyze the analgesic effects of TEA versus TPVB after thoracoscopic surgery.

Methods: We systematically searched RCTs published by October 26, 2020, in PubMed, EMBASE, and Cochrane library and conducted a meta-analysis to analyze the analgesic effects of TEA versus TPVB after thoracoscopic surgery. The primary measure was postoperative pain score, and the secondary measures were postoperative 24-hour usage of opioids, hypotension, postoperative nausea, and vomiting.

Results: A total of 458 patients from five RCTs were included in this study. After thoracoscopic surgery, the numerical rating scale (NRS) score for resting pain was higher in the TPVB group than in the TEA group at 1-2 hours and 4-6 hours after surgery $(\mathrm{MD}=0.44$, $95 \% \mathrm{CI}=0.24$ to $0.64, \mathrm{P}<0.0001, \mathrm{I} 2=0 \%$; $\mathrm{MD}=0.47,95 \% \mathrm{CI}=0.23$ to $0.70, \mathrm{P}<0.0001$, $\mathrm{I} 2=0 \%$ ). The postoperative 24-hour usage of morphine was higher in the TPVB group than in the TEA group $(\mathrm{SMD}=0.67 ; 95 \% \mathrm{CI}=0.03$ to $1.31 ; \mathrm{P}=0.04 ; \mathrm{I} 2=84 \%$ ). The incidence of hypotension was significantly lower in the TPVB group than in the TEA group (OR = $4.52 ; 95 \% \mathrm{CI}=2.03$ to $10.10 ; \mathrm{P}=0.0002 ; \mathrm{I}^{2}=0 \%$ ). No significant between-group difference was observed in postoperative nausea and vomiting (PONV).

Conclusion: Compared with TPVB, TEA provides statistically significant but clinically unimportant short-term benefits following thoracoscopic surgery.

Keywords: thoracic paravertebral block, thoracic epidural anesthesia, thoracoscopic surgery, meta-analysis

\section{Introduction}

Thoracic movement, intercostal nerve injury, and thoracic catheter-induced pleura stimulation can cause severe pain in patients after thoracic surgery, ${ }^{1}$ resulting in chronic pain in up to $50 \%$ of patients after thoracotomy. ${ }^{2}$ TEA is recommended by relevant guidelines as the gold standard of analgesia after thoracotomy. ${ }^{3}$ Video-assisted thoracoscopic surgery (VATS) is superior to thoracotomy in improving patient outcomes and reducing pain and has become the main surgical approach. However, postoperative pain is still an issue. ${ }^{4}$ Pain increases the incidence of hypoxemia and hypercapnia, increases myocardial oxygen consumption, and increases the risk of arrhythmia and myocardial ischemia. Therefore, reducing postoperative pain reduces bed rest and pulmonary complications. ${ }^{5}$ As the first 
choice for analgesia after thoracotomy, TEA is associated with major complications, and its application is limited by complications such as epidural hematoma and the potential for severe spinal cord injuries. ${ }^{6}$ In 1905, Sellheim et al, from Leipzig, Germany, first used paravertebral block as an alternative to central nerve block during obstetric surgery. ${ }^{7}$ TPVB blocks only one side, thereby preserving the respiratory and sympathetic function of the other side, which may help reduce pulmonary complications, hypotension, and urinary retention. ${ }^{8}$ With the advancement of ultrasound technology, TPVB is being increasingly used for analgesia after thoracic surgery. At present, both TEA and TPVB are widely used in patients undergoing thoracic surgery. A previous meta-analysis indicated that as an alternative to TEA after thoracotomy, TPVB demonstrates similar analgesic effects with fewer complications. ${ }^{9}$ However, it is unknown if TEA and TPVB have similar or different analgesic effects and side effects after VATS. In this study, we conducted a meta-analysis of TPVB versus TEA after VATS to investigate the pros and cons of each method, in order to provide clinical evidence for post-VATS analgesia.

\section{Methods}

\section{Search Strategy and Selection Criteria}

This meta-analysis was performed in accordance with PRISMA (Preferred Reporting Items for Systematic Reviews and Meta-Analyses) guidelines. We searched PubMed, EMBASE, and Cochrane Library for articles published up until October 26, 2020. See Appendix 1 for specific keywords. Two researchers (Xiaolong Liang and Ran An) independently searched and selected eligible random controlled trials (RCTs). Any discrepancy was resolved after discussion with a third researcher (Qi Chen). This meta-analysis was registered prospectively in the PROSPERO database (CRD42020216350).

The inclusion criteria were as follows: 1) adult patients scheduled for thoracoscopic surgery; 2) TPVB in the intervention group; 3) TEA in the control group; 4) RCTs; and 5) articles written in English.

The exclusion criteria were as follows: 1) RCTs with incomplete or missing data; 2) conference proceedings without detailed study data.

\section{Data Extraction and Analysis}

We extracted the following information: author; number of patients; nerve block approach; type, strength, and dose of nerve block drugs; surgical approach; postoperative analgesia pump formulation; and primary measures. The data were independently extracted by two researchers, and any discrepancy was resolved via discussion. For graphic values, WebPlotDigitizer was used to extract numerical data. ${ }^{10}$ Moreover, we contacted the corresponding author to obtain additional data as needed. The primary measure was postoperative pain score. The secondary measures were postoperative 24-hour usage of morphine, hypotension and PONV.

\section{Quality Assessment}

The Cochrane's risk of bias assessment tool and the Jadad score were used to assess the quality of included RCTs. ${ }^{11}$ The Cochrane's risk of bias assessment tool assesses selection bias, implementation bias, measurement bias, followup bias, reporting bias, and other biases. The Jadad score (total: 5 points) includes randomization ( $0-2$ points), blinding (0-2 points), and early withdrawal and loss to follow-up ( $0-1$ points). A Jadad score $<2$ indicates low quality, and a Jadad score $\geq 3$ indicates high quality.

\section{Statistical Analysis}

Review Manager V.5.3 was used for data analysis (Cochrane Collaboration), with $95 \%$ confidence intervals (CIs) provided. For continuous variables, an inverse variance method was used to calculate the mean difference (MD) (postoperative pain score at 1-2 hours, 4-6 hours, 24 hours, and 48 hours) and standard mean difference (SMD) of the postoperative use of morphine. For dichotomous variables, the relative risk (RR) of PONV was calculated with the MantelHaenszel method. If only one RCT was available, the results were reported descriptively. For all results, $\mathrm{P}<0.05$ indicated statistical significance, and $\mathrm{I}^{2}>50 \%$ indicated significant heterogeneity. Due to the inherent heterogeneous nature of block performance by different practitioners, a random effects model was used in this analysis. Sensitivity analysis and subgroup analysis were performed in the case of significant heterogeneity $\left(\mathrm{I}^{2}>50 \%\right)$. Stata v15.1 was used for sensitivity analysis. We did not assess publication bias due to the limited number of included RCTs. For the meta-analysis, we used the method described by Wan and Luo to convert the median, interquartile range (IQR), and range values into mean values and standard deviations (SDs). ${ }^{12,13} \mathrm{~A}$ visual analog scale (VAS), numerical rating scale (NRS) or verbal rating scale (VRS) was used to assess pain, and the score was then converted to a $0-10$ scale for statistical analysis. 


\section{Results}

\section{Literature Search and Selection and Quality Assessment}

A detailed flowchart of literature search retrieval is provided in Figure 1. A total of 267 relevant articles were initially retrieved. Finally, five eligible RCTs were included in the meta-analysis. ${ }^{14-18}$

The five eligible articles were carefully reviewed; their characteristics are provided in Table 1. The RCTs enrolled a total of 458 patients, and the results were published between 2015 and 2020. We contacted the authors to request the original data for two RCTs in which some of the postoperative pain scores were unclear in the figures. Huang responded, ${ }^{17}$ but Sylweriusz did not. ${ }^{16}$ Four RCTs used ultrasound-guided TPVB. One RCT used traditional TPVB. All five articles reported postoperative pain scores, three articles reported postoperative use of morphine, and three articles reported the incidence of hypotension and
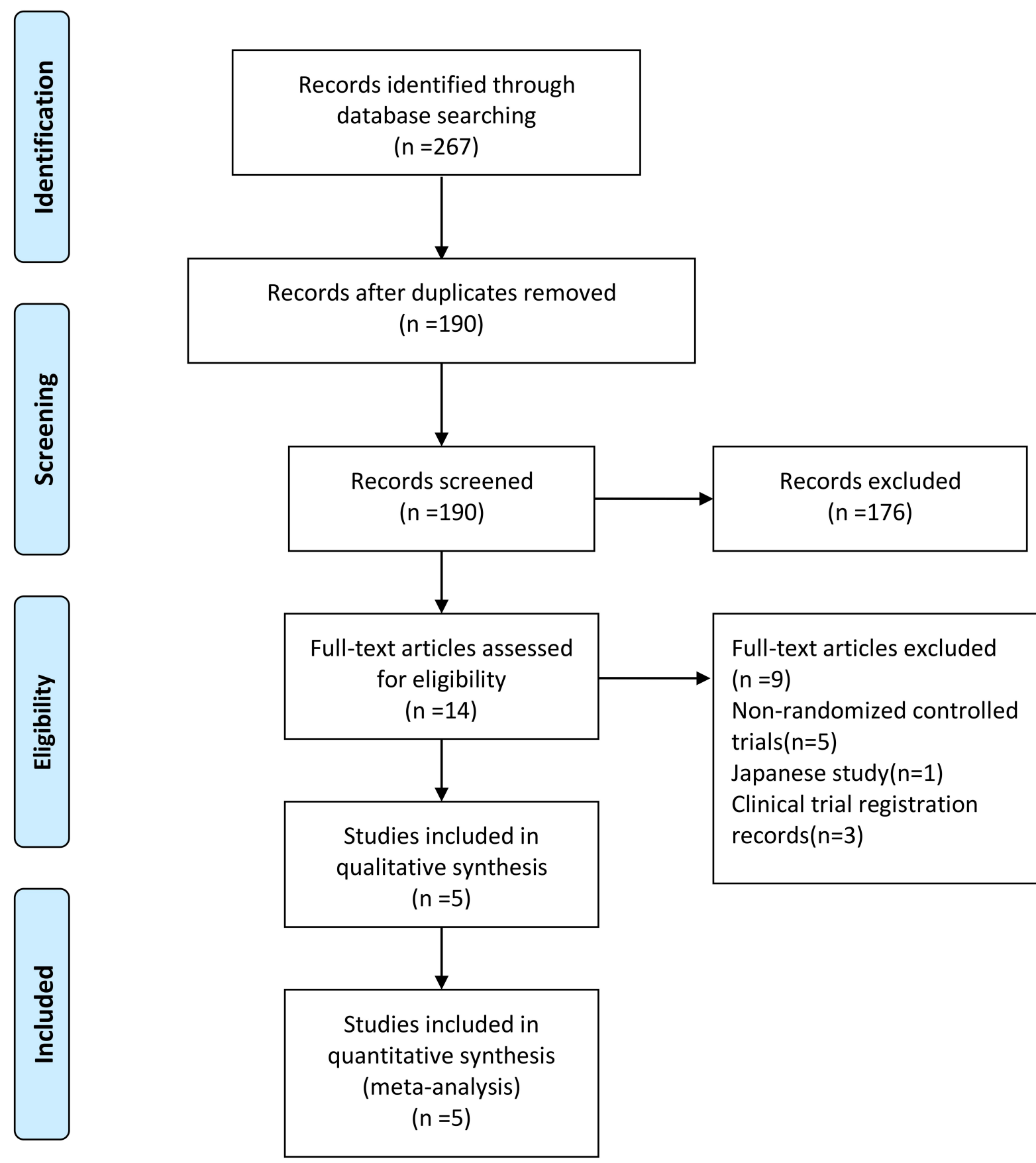

Full-text articles excluded

( $n=9)$

Non-randomized controlled trials $(n=5)$ Japanese $\operatorname{study}(\mathrm{n}=1)$

Clinical trial registration

$\operatorname{records}(n=3)$

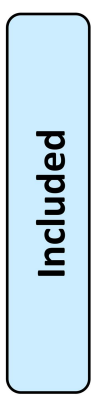

Figure I PRISMA flow diagram. 
Table I Characteristics of Included Studies

\begin{tabular}{|c|c|c|c|c|c|c|}
\hline Study & $\begin{array}{l}\text { Interventions } \\
\text { Group/Control } \\
\text { Group }\end{array}$ & $\mathbf{N}$ & Drug & Type of Surgery & $\begin{array}{l}\text { Primary } \\
\text { Outcome }\end{array}$ & $\begin{array}{l}\text { JADAD } \\
\text { Score }\end{array}$ \\
\hline $\begin{array}{l}\text { Yeap et al, }{ }^{14} \\
2020\end{array}$ & PVB-S/PVB-C/TEA & $40 / 40 / 40$ & $\begin{array}{l}0.5 \% \text { ropivacaine } 30 \mathrm{~mL} / 0.2 \% \text { ropivacaine } 10 \mathrm{~mL} \\
\mathrm{~h}^{-1} / 0.125 \% \text { bupivacaine }\end{array}$ & $\begin{array}{l}\text { Wedge, Lobectomy, } \\
\text { Pleurodesis, Decortication, } \\
\text { Mediastina }\end{array}$ & $\begin{array}{l}\text { VAS, Opioid } \\
\text { Usage }\end{array}$ & 3 \\
\hline $\begin{array}{l}\text { Ding et al, }{ }^{15} \\
2018\end{array}$ & PVB-S/PVB-S/TEA & $36 / 34 / 32$ & $\begin{array}{l}0.5 \% \text { ropivacaine } 15 \mathrm{~mL} / 0.5 \% \text { ropivacaine } \\
\text { combined with dexmedetomidine } 15 \mathrm{~mL} / 0.5 \% \\
\text { ropivacaine }\end{array}$ & Lobectomy & $\begin{array}{l}\text { Opioid Usage, } \\
\text { VRS, HR and } \\
\text { MAP }\end{array}$ & 4 \\
\hline $\begin{array}{l}\text { Sylweriusz } \\
\text { et al, }{ }^{16} 2016\end{array}$ & PVB-S/TEA & $26 / 25$ & $0.25 \%$ bupivacaine $20 \mathrm{~mL} / 0.25 \%$ bupivacaine & Lobectomy & $\begin{array}{l}\text { VAS, Opioid } \\
\text { Usage }\end{array}$ & 4 \\
\hline $\begin{array}{l}\text { Huang } \\
\text { et al, }{ }^{17} 2020\end{array}$ & PVB-C/PVB-C/TEA & $45 / 32 / 39$ & $\begin{array}{l}0.25 \% \text { ropivacaine } 0.25 \mathrm{mg} \mathrm{kg}^{-1} \mathrm{~h}^{-1} / 0.25 \% \\
\text { ropivacaine } 0.25 \mathrm{mg} \mathrm{kg}^{-1} \mathrm{~h}^{-1} / 0.25 \% \text { ropivacaine }\end{array}$ & $\begin{array}{l}\text { Thoracoscopic surgery for } \\
\text { lung cancer }\end{array}$ & $\begin{array}{l}\text { Opioid Usage, } \\
\text { NRS, HR and } \\
\text { MAP }\end{array}$ & 4 \\
\hline $\begin{array}{l}\text { Okajima } \\
\text { et al, }{ }^{18} 2014\end{array}$ & PVB-C/TEA & $36 / 33$ & $\begin{array}{l}0.1 \% \text { ropivacaine } 6 \mathrm{~mL} \mathrm{~h}^{-1} / 0.25-0.375 \% \\
\text { ropivacaine }\end{array}$ & $\begin{array}{l}\text { Lobectomy Segmentectomy } \\
\text { Wedge resection }\end{array}$ & VRS & 5 \\
\hline
\end{tabular}

PONV. The results from the Cochrane's risk of bias assessment tool are provided in Figure 2. The Jadad score is shown in Table 1.

\section{Primary Measure: Postoperative Scores for Resting and Coughing Pain at $\mathrm{I}-2$ Hours, 4-6 Hours, 24 Hours, and 48 Hours}

All five RCTs analyzed pain score over time for TPVB versus TEA after thoracoscopic surgery. In the resting state, postoperative pain scores at 1-2 hours and 4-6 hours (Figure 3) were not significantly higher in the TPVB group than in the TEA group ( $\mathrm{MD}=0.44,95 \% \mathrm{CI}=0.24$ to $0.64, \mathrm{P}<0.0001, \mathrm{I}^{2}$ $=0 \% ; \mathrm{MD}=0.47,95 \% \mathrm{CI}=0.23$ to $0.70, \mathrm{P}<0.0001, \mathrm{I}^{2}=0 \%$; $\mathrm{P}<0.05)$. No heterogeneity was observed. No significant between-group differences were observed at 24 or 48 hours ( $\mathrm{MD}=0.39,95 \% \mathrm{CI}=-0.25$ to $1.04, \mathrm{P}=0.23, \mathrm{I}^{2}=78 \%$; $\mathrm{MD}$ $=0.35,95 \% \mathrm{CI}=-0.05$ to $\left.0.75, \mathrm{P}=0.09, \mathrm{I}^{2}=56 \%\right)$. In the coughing state (Figure 4), no significant between-group differences were observed at 1-2, 24, or 48 hours ( $\mathrm{MD}=0.22,95 \%$ $\mathrm{CI}=-0.20$ to $0.65, \mathrm{P}=0.31, \mathrm{I}^{2}=45 \% ; \mathrm{MD}=-0.03,95 \%$ $\mathrm{CI}=-1.27$ to $1.22, \mathrm{P}=0.97, \mathrm{I}^{2}=92 \% ; \mathrm{MD}=0.03,95 \% \mathrm{CI}$ $=-0.63$ to $0.69, \mathrm{P}=0.93, \mathrm{I}^{2}=79 \%$ ). At $4-6$ hours, the pain score was not significantly higher in the TPVB than in the TEA group $\left(\mathrm{MD}=0.46,95 \% \mathrm{CI}=0.15\right.$ to $0.77, \mathrm{P}=0.003, \mathrm{I}^{2}=$ $0 \% ; \mathrm{P}<0.05)$. At 24 hours and 48 hours, $\mathrm{I}^{2}$ was $>50 \%$, indicating significant heterogeneity, and subgroup analysis was performed to identify the source of heterogeneity. The results showed that in the resting state (Figure 5), the pain score was higher in the single-injection TPVB group (TPVB-S group) than in the TEA group ( $\mathrm{MD}=0.90 ; 95 \% \mathrm{CI}=0.47-$ $1.32 ; \mathrm{P}<0.05 ; \mathrm{I}^{2}=0 \%$ ), while no significant difference was observed in postoperative analgesic effects between the continuous TPVB group (TPVB-C group) and the TEA group $\left(\mathrm{MD}=0.14 ; 95 \% \mathrm{CI}=-0.95\right.$ to $\left.1.23 ; \mathrm{P}=0.80 ; \mathrm{I}^{2}=83 \%\right)$. Moreover, no significant between-group difference was observed in the coughing state (Figure 6). Sensitivity analysis was performed by omitting one study in each turn. After the removal of the study by Sylweriusz, ${ }^{16}$ the resting pain score at 24 hours changed from $(\mathrm{MD}=0.39,95 \% \mathrm{CI}=-0.25$ to 1.04 , $\mathrm{P}=0.23, \mathrm{I} 2=78 \%)$ to $(\mathrm{MD}=0.73,95 \% \mathrm{CI}=0.28$ to 1.18 , $\mathrm{P}=0.002, \mathrm{I} 2=57 \%$ ). After the study by Ding was removed, ${ }^{15}$ the pain score in the resting state at 48 hours changed from $(\mathrm{MD}=0.35,95 \% \mathrm{CI}=-0.05$ to $0.75, \mathrm{P}=0.09, \mathrm{I} 2=56 \%)$ to $(\mathrm{MD}=0.50,95 \% \mathrm{CI}=0.21$ to $0.80, \mathrm{P}<0.05, \mathrm{I} 2=2 \%$ ). According to the number of studies included, subgroup analysis was performed with the mean operative time of 160 minutes as the boundary to explore the effect of differences in time between groups on outcomes (Appendix 2).

\section{Postoperative 24-Hour Usage of Morphine, Hypotension, and PONV}

Three RCTs were included in the analysis of postoperative 24hour usage of morphine (Figure 7) with a random effects model $(\mathrm{SMD}=0.67 ; 95 \% \mathrm{CI}=0.03$ to $1.31 ; \mathrm{P}=0.04$; $\mathrm{I}^{2}=84 \%$ ). The results showed that more opioids were required in the TPVB group than in the TEA group. Three RCTs were included in the analysis of hypotension (Figure 8) with 


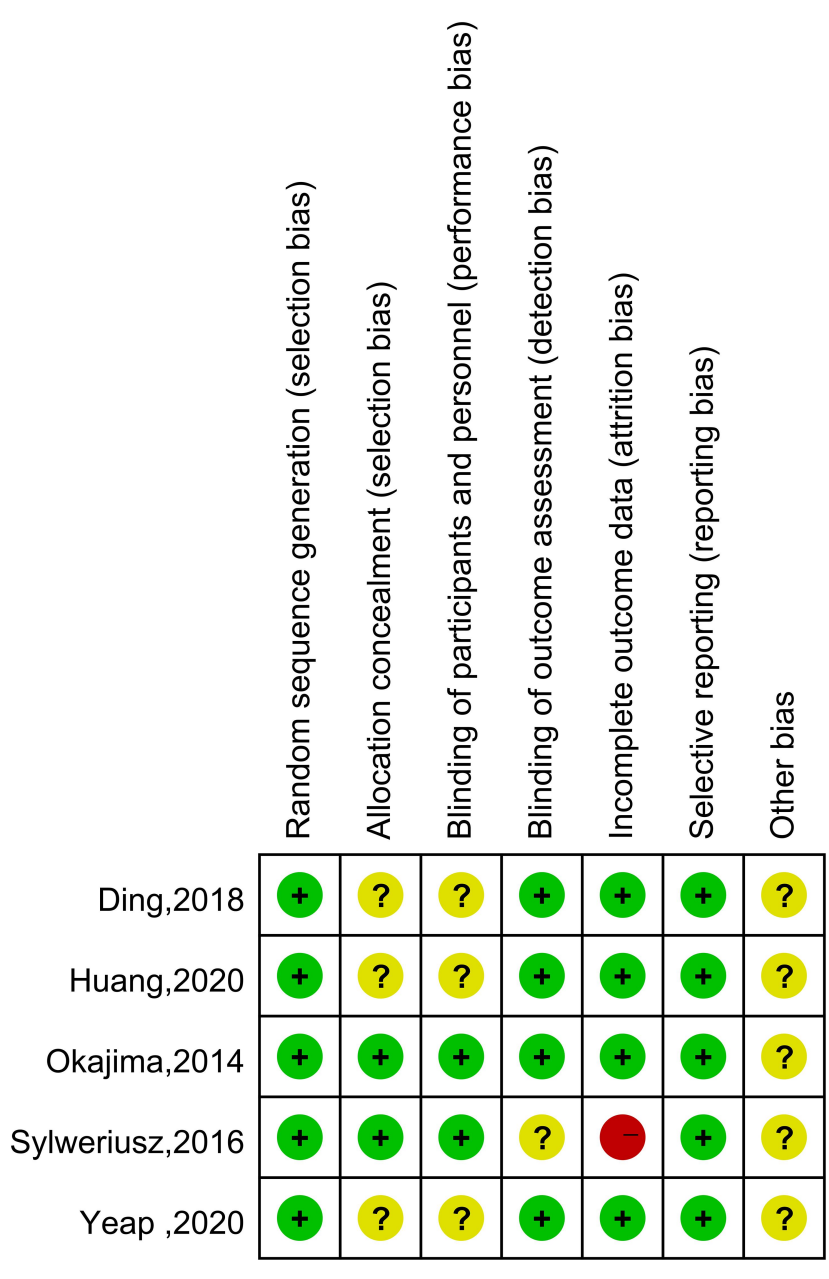

Figure 2 Risk of bias assessment using Cochrane criteria.

a random effects model $(\mathrm{OR}=4.52 ; 95 \% \mathrm{CI}=2.03$ to 10.10 ; $\mathrm{P}=0.0002 ; \mathrm{I} 2=0 \%$ ). Compared with the TEA group, the incidence of hypotension was significantly lower in the TPVB group. In addition, three RCTs were included in the analysis of PONV (Figure 9) with a random effects model $(\mathrm{RR}=0.59$; $95 \% \mathrm{CI}=0.26$ to $1.33 ; \mathrm{P}=0.20 ; \mathrm{I}^{2}=51 \%$ ), and the results showed no significant between-group differences.

\section{Discussion}

Analysis of the pooled data revealed a disadvantage in postoperative analgesia in the TPVB group (1-2 hours, 4-6 hours) compared with the TEA group. Our metaanalysis showed a difference in NRS scores of less than $1 \mathrm{~cm}$. Cepeda et al found that the meaning of a change in the NRS depends upon the intensity of the initial pain, and a NRS change of $1.3 \mathrm{~cm}$ was the threshold for minimal pain relief for moderate baseline pain intensity, whereas the minimum clinically significant decrease was $1.8 \mathrm{~cm}$ for severe baseline pain intensity. ${ }^{19}$ Consequently, the clinical significance of our finding is limited. Higher opioid consumption was observed in the TPVB group during the first 24 hours. Compared with the TEA group, the incidence of hypotension was significantly higher in the TPVB group. Moreover, the analgesic efficacy of TPVB was similar to that of TEA based on pain scores at 24 or 48 hours or rates of PONV.

In the early resting state (1-2 hours and 4-6 hours) and coughing state (4-6 hours) after thoracoscopic surgery, TEA was superior to TPVB in terms of analgesic effects. The heterogeneity was small and had statistical significance. Potential causes include the following. 1) Anatomy is a likely cause. The paravertebral space is a potential space where local anesthetics block the dorsal branch, ventral branch, and sympathetic nerve chain that extend from the spinal canal to exert analgesia effects with variations in drug diffusion. ${ }^{20}$ On the other hand, the space in the spinal canal is conducive to drug diffusion with definitive blocking effects. 2) In the TEA group, local anesthetics were pumped continuously after operation, and the analgesic effect was definite. In the TPVB group, there were two conditions: single-injection TPVB and continuous TPVB. The analgesic effect of singleinjection TPVB was shorter due to the time of drug action, resulting in an inferior analgesic effect compared with the TEA group. An indwelling paravertebral catheter may theoretically provide continuous blocking. ${ }^{21,22}$ Yeap et al showed that continuous TPVB is time consuming and provides an analgesic effect that is not significantly different from that of a single block, suggesting that the continuous analgesic effect of paravertebral tube block is not ideal and not the best choice for paravertebral block. Termpornlert et al indicated that the effects of continuous TPVB are unpredictable. ${ }^{23}$ One possible way to circumvent the unpredictable spread of local anesthetic through a catheter is to use an intermittent bolus injection of a relatively large volume instead of continuous infusion. No significant differences in the postoperative pain score were observed between TPVB and TEA at 24 and 48 hours. $\mathrm{I}^{2}$ was greater than $50 \%$, highlighting a major limitation of the considerable interstudy heterogeneity. Subgroup analysis revealed that the analgesia score in the resting state was higher for single-injection TPVB than for TEA at 24 or 48 hours after the operation, whereas the effect of continuous TPVB was not significantly different from that of TEA. This finding suggests that the time of drug action may be responsible for the difference in postoperative pain scores. Another likely 


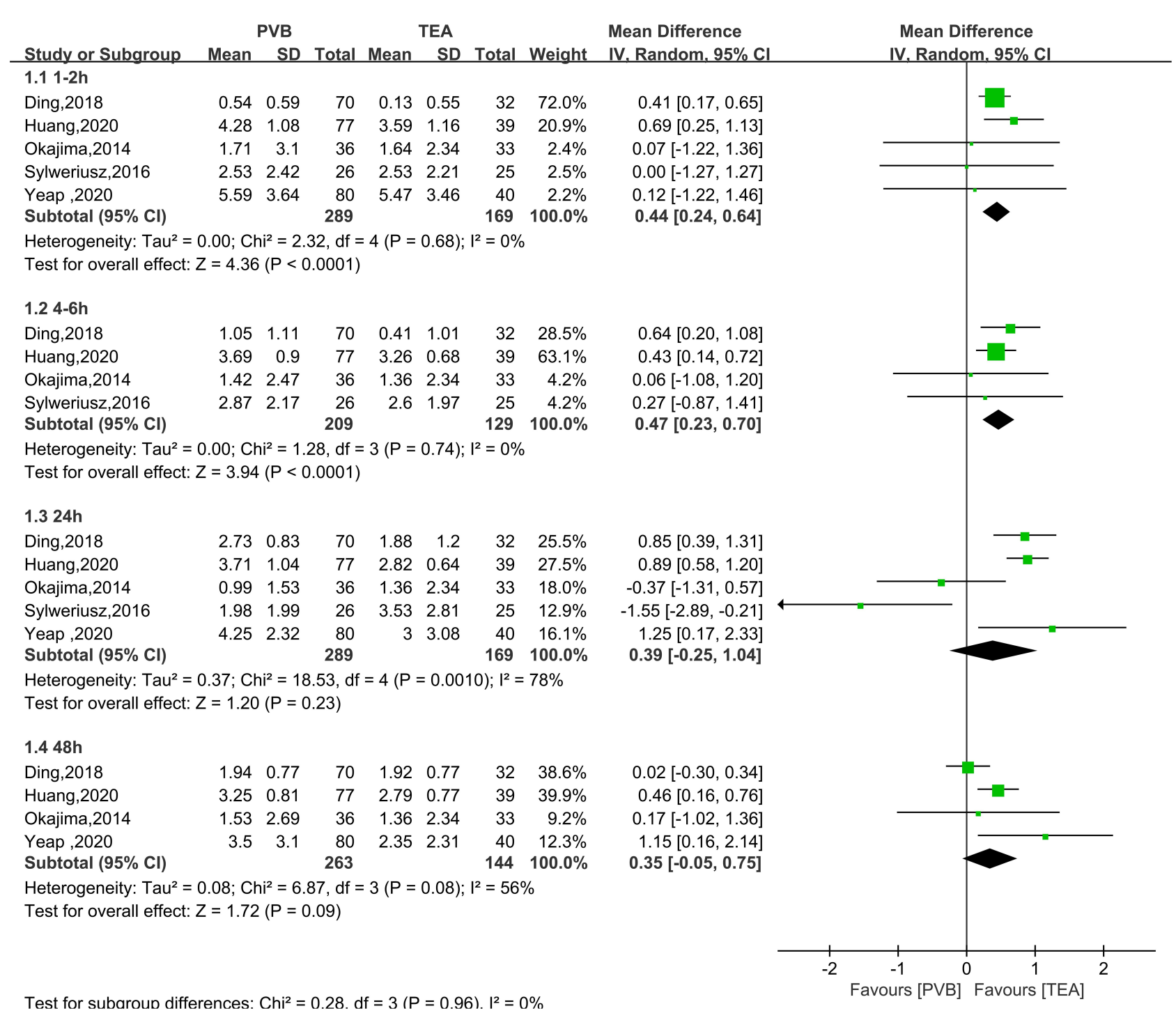

Figure 3 Forest plot of postoperative scores for resting pain at I-2 hours, 4-6 hours, 24 hours, and 48 hours.

source of heterogeneity is differences in practitioner skills between the two types of block, as the studies did not report how much experience practitioners had with TEA and TPVB. The type of surgery is one of the important factors for postoperative acute pain, ${ }^{24}$ although we limited thoracoscopic surgery in our inclusion criteria, there were differences in the specific surgical methods, such as the number of the thoracoscopy ports, wedge and lobectomy, and the number and location of postoperative chest tubes. There was no significant difference in operative time between the experimental group and the control group in the included studies, but dividing the two groups into two subgroups for subgroup analysis according to the mean operative time of 160 minutes showed that operative time may have no effect on the early (1-2 hours and 4-6 hours) postoperative pain score. Differences in the type, concentration, and injection volume of local anesthetics may also be contributing factors. Such discrepancies would explain why some studies reported results favoring TEA while others reported results favoring TPVB. Sensitivity analyses in which individual studies were successively removed showed that the results in the early postoperative time period (1-2 hours and 4-6 hours) were stable and reliable. After removal of the study by Sylweriusz, the pain score in the resting state at 24 hours after surgery changed. Luyet et al showed that up to $32 \%$ of TPVB catheters were misplaced using guiding landmarks. ${ }^{25}$ In the study by Sylweriusz, the success rate of TEA was significantly lower than that of TPVB when analyzed in a blinded manner; we believe that this difference may be 


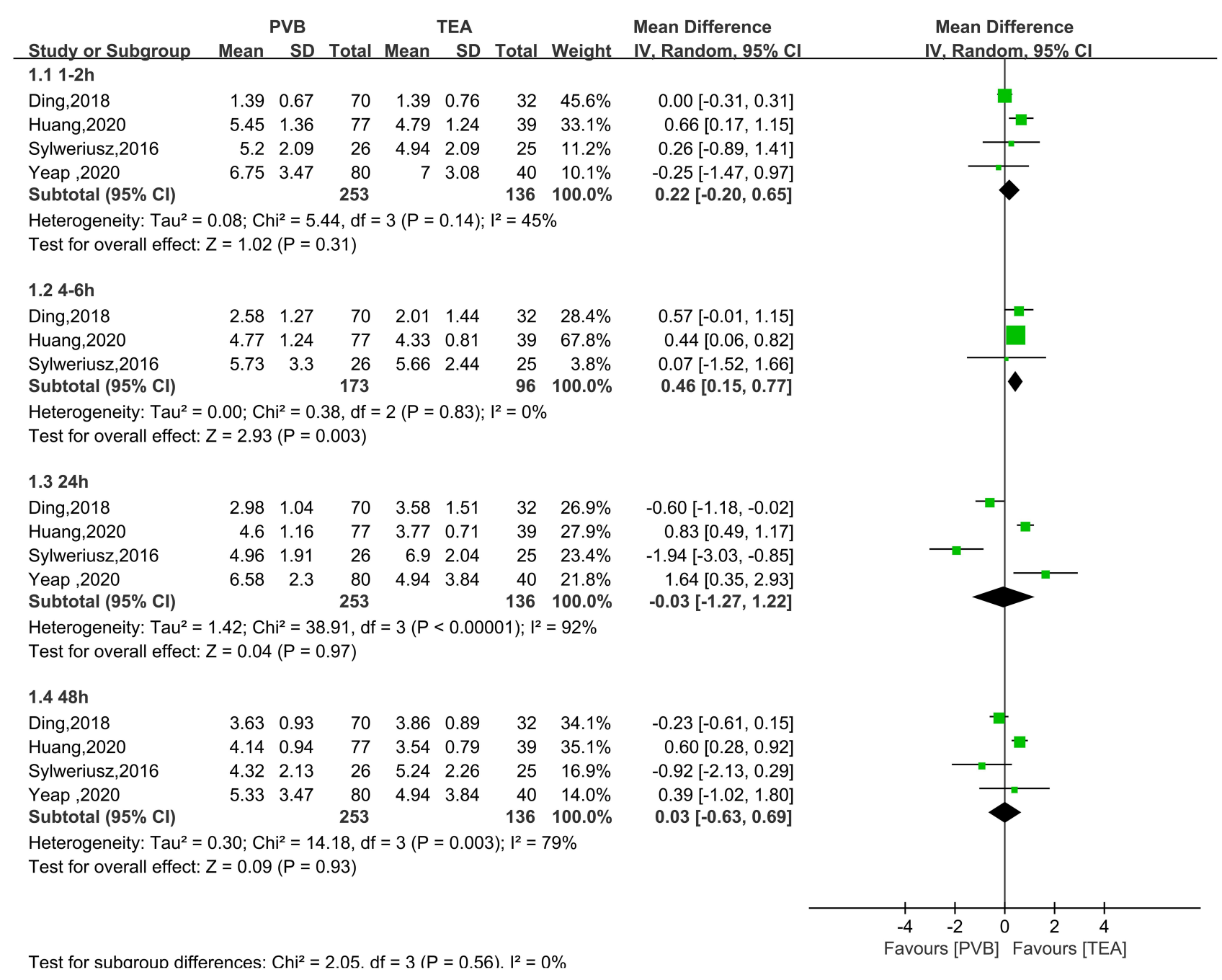

Figure 4 Forest plot of postoperative scores for coughing pain at I-2 hours, 4-6 hours, 24 hours, and 48 hours.

due to the anesthesiologist's proficiency, which may be a source of heterogeneity. In Ding's study, the TPVB group received adjuvant dexmedetomidine, which may prolong the action time of TPVB. Due to the small sample size, subgroup analysis could not be conducted, and the results need to be confirmed with a larger sample size. However, this difference in treatment may be responsible for the heterogeneity of the resting pain assessment in this group 48 hours after surgery. Intraoperative use of opioids may affect pain severity, especially in the early postoperative period, and we attempted a subgroup analysis by opioid dosage. In three studies, ${ }^{16-18}$ intraoperative opioid dosage was recorded in detail, and there was no statistical difference in intra-group opioid dosage. The sample size was too small for subgroup analysis, so we could not rule out the influence of intraoperative opioid dosage on our results, which may be one of the sources of heterogeneity.
In addition, heterogeneity could arise from the lack of standardization of the boundaries of the block levels in the included studies. We are cautious about the outcome of pain score at 24 and 48 hours after surgery.

The TPVB group required more opioids during the first 24 hours after surgery than did the TEA group, a result that was consistent with higher scores for resting pain in the TPVB group in the early stages (1-2 hours and 4-6 hours) after surgery. Notably, Okajima et al used fentanyl, which enters the blood circulation immediately after dosing, with the ability to exert analgesic effects and induce PONV because of the presence of opioid receptors on the spinal canal, ${ }^{18}$ thereby increasing the incidence of nausea and vomiting. The incidence of hypotension was significantly lower in the TPVB group than in the TEA group, which was one of the advantages of the TPVB group. TPVB blocks only one side, thereby preserving the 


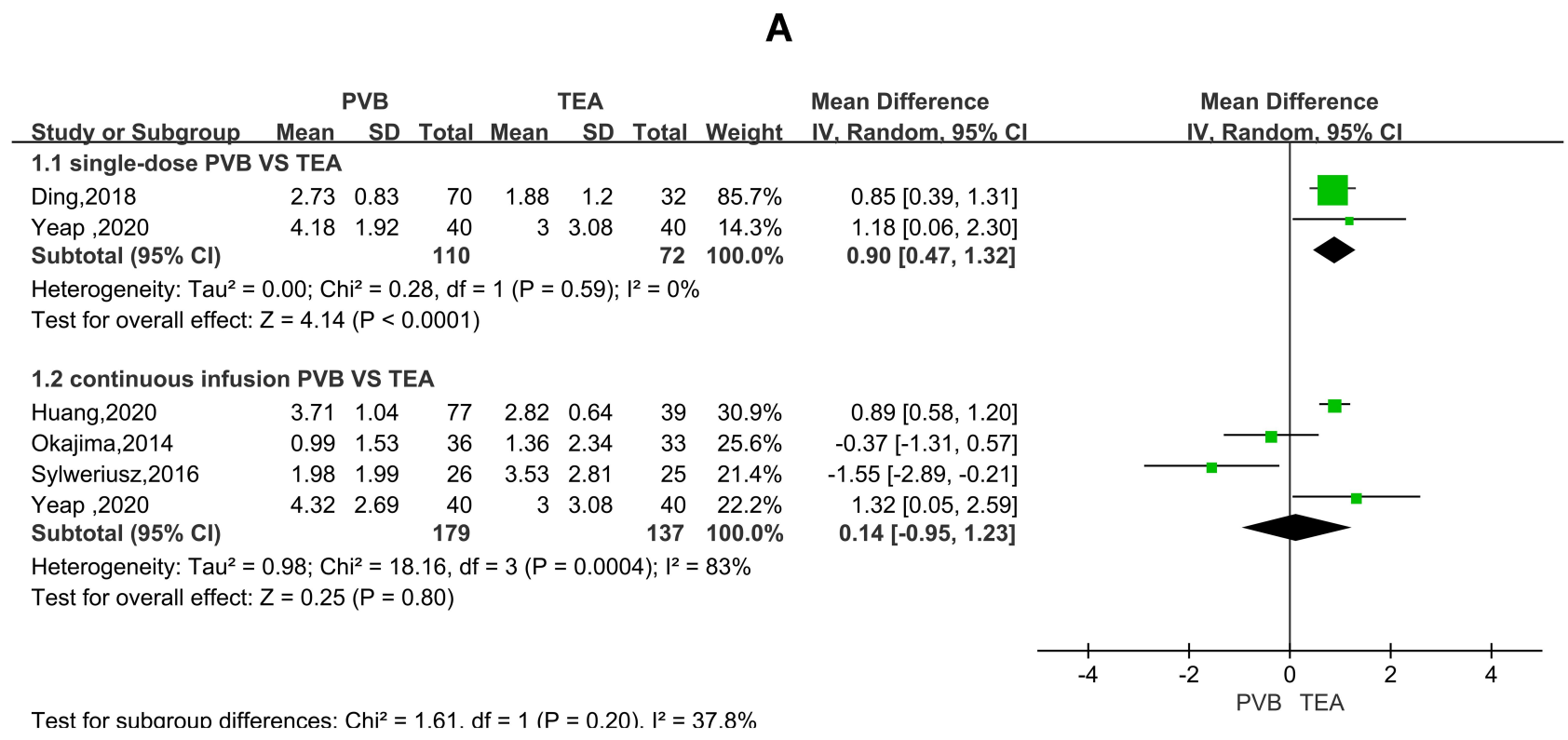

B

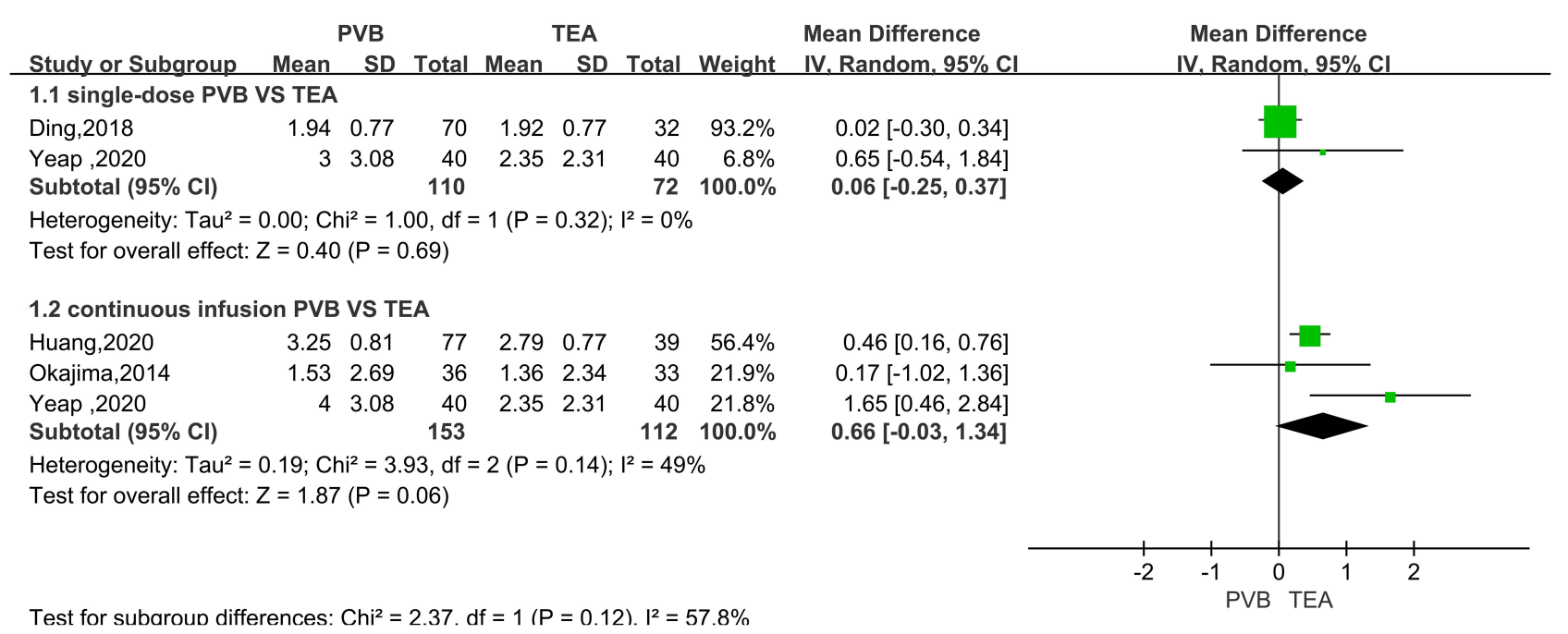

Figure 5 Forest plot of the subgroup analysis of postoperative scores for resting pain at 24 hours (A) and 48 hours (B).

respiratory and sympathetic function of the other side, which may help reduce hypotension. ${ }^{8}$ For patients with potential hypotension, TPVB should be selected over TEA as the postoperative analgesia.

TEA is the gold standard of anesthesia after thoracotomy; however, it has significant side effects and is absolutely contraindicated in patients with coagulation disorders. After thoracotomy, TPVB is considered an alternative to TEA. In 2013, Steinthorsdottir et al reviewed TPVB and TEA after thoracoscopic surgery but did not reach any conclusion due to limited RCTs on TPVB versus TEA after VATS at the time. ${ }^{26}$ The meta-analysis of Hu et al showed that the analgesic effect of TPVB after thoracotomy was lower than that of non-paravertebral block, with fewer side effects. ${ }^{27}$ However, Hu et al did not compare TPVB with TEA, and it was unclear which analgesic method was more suitable for thoracotomy. Baidya et al conducted a meta-analysis of postoperative scores for resting and coughing pain at 4-8 hours and found that TEA and TPVB showed similar analgesic effects after thoracotomy. ${ }^{9}$ Yeung et al found that TPVB was as effective as TEA in controlling acute pain after thoracotomy. ${ }^{28}$ They did not include VATS for comparison. 


\section{A}

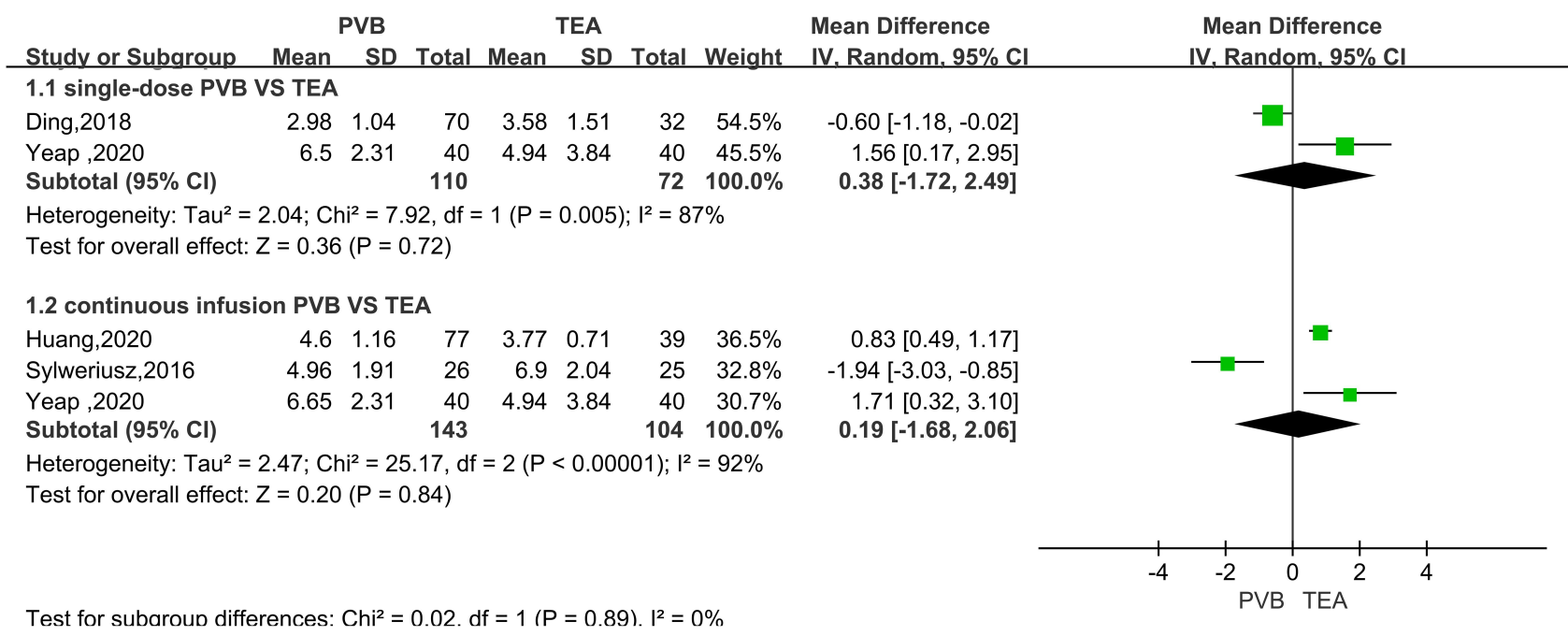

B

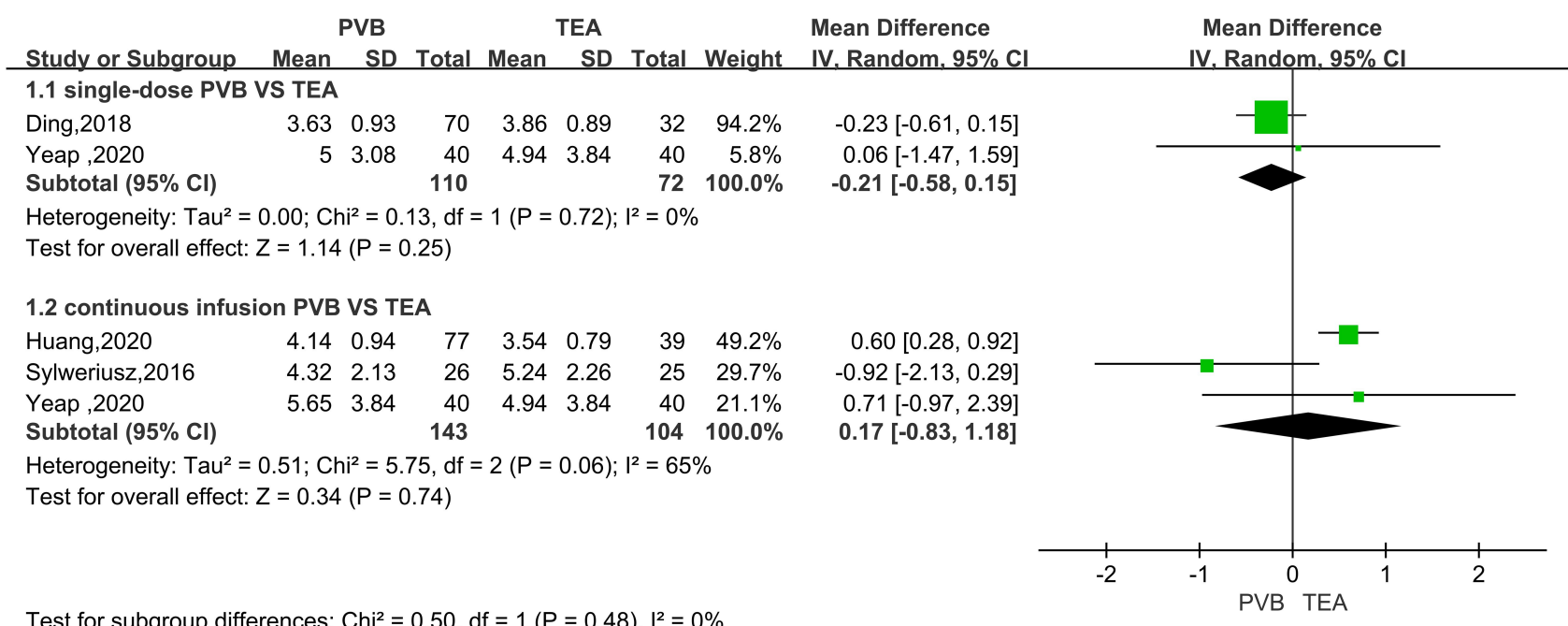

Figure 6 Forest plot of the subgroup analysis of postoperative scores for coughing pain at 24 hours (A) and 48 hours (B).

\begin{tabular}{|c|c|c|c|c|c|c|c|c|c|c|c|c|}
\hline \multirow[b]{2}{*}{ Study or Subgroup } & \multicolumn{2}{|r|}{ PVB } & \multicolumn{3}{|r|}{ TEA } & \multirow[b]{2}{*}{ Total } & \multirow[b]{2}{*}{ Weight } & \multicolumn{2}{|l|}{ Std. Mean Difference } & \multirow{2}{*}{\multicolumn{2}{|c|}{$\begin{array}{r}\text { Std. Mean Difference } \\
\text { IV. Random, } 95 \% \mathrm{CI}\end{array}$}} & \\
\hline & Mean & SD & Total & Mean & SD & & & IV. Random, $95 \% \mathrm{Cl}$ & & & & \\
\hline Huang,2020 & 8.85 & 7.54 & 77 & 2.24 & 4.64 & 39 & $34.5 \%$ & $0.98[0.57,1.38]$ & & & & \\
\hline Sylweriusz,2016 & 0.34 & 0.33 & 26 & 0.37 & 0.28 & 25 & $30.9 \%$ & $-0.10[-0.65,0.45]$ & & & & \\
\hline Total $(95 \% \mathrm{Cl})$ & & & 183 & & & 104 & $100.0 \%$ & $0.67[0.03,1.31]$ & & & & \\
\hline $\begin{array}{l}\text { Heterogeneity: } \mathrm{Tau}^{2}= \\
\text { Test for overall effect: }\end{array}$ & $\begin{array}{l}.27 ; \mathrm{Cr} \\
=2.04\end{array}$ & $\begin{array}{l}i^{2}=12 \\
(P=0 .\end{array}$ & $\begin{array}{l}29, \mathrm{df}= \\
04)\end{array}$ & $2(P=$ & 0.002); & $2=84^{\circ}$ & & & -4 & -2 & TEA & 4 \\
\hline
\end{tabular}

Figure 7 Forest plot of postoperative 24-hour usage of morphine.

By contrast, we found that the NRS scores of TPVB for early postoperative (1-2 hours and 4-6 hours) pain after thoracoscopic surgery were inferior to those of TEA. However, differences in clinical patient-based assessments of pain outcomes may not be significant. With the development of ultrasound, TPVB has been chosen by more and more people as analgesia for thoracotomy, and there is no consensus on the standard postoperative analgesia for thoracoscopic 


\begin{tabular}{|c|c|c|c|c|c|c|c|c|c|c|}
\hline Study or Subgroup & $\begin{array}{r}\text { TEA } \\
\text { Events }\end{array}$ & Total & $\begin{array}{l}\text { PVB } \\
\text { Events }\end{array}$ & Total & Weight & $\begin{array}{c}\text { Odds Ratio } \\
\text { M-H. Random, } 95 \% \mathrm{Cl}\end{array}$ & & $\begin{array}{r}\text { Odds } \\
M-H, \text { Rand }\end{array}$ & $\begin{array}{l}\text { Ratio } \\
\text { lom. } 95 \% \mathrm{Cl}\end{array}$ & \\
\hline Ding,2018 & 11 & 32 & 9 & 70 & $63.0 \%$ & $3.55[1.29,9.76]$ & & & & \\
\hline Okajima,2014 & 7 & 33 & 1 & 36 & $13.9 \%$ & $9.42[1.09,81.37]$ & & & & \\
\hline Sylweriusz,2016 & 8 & 25 & 2 & 26 & $23.1 \%$ & $5.65[1.06,29.98]$ & & & & \\
\hline Total $(95 \% \mathrm{Cl})$ & & 90 & & 132 & $100.0 \%$ & $4.52[2.03,10.10]$ & & & & \\
\hline Total events & 26 & & 12 & & & & & & & \\
\hline \multicolumn{6}{|c|}{$\begin{array}{l}\text { Heterogeneity: } \mathrm{Tau}^{2}=0.00 ; \mathrm{Chi}^{2}=0.75, \mathrm{df}=2(P=0.69) ; \mathrm{I}^{2}=0 \% \\
\text { Test for overall effect: } Z=3.69(P=0.0002)\end{array}$} & & 0.02 & $\begin{array}{l}0.1 \\
\text { Favours [TEA] }\end{array}$ & $\begin{array}{lc}1 & 10 \\
& \text { Favours [PVB] }\end{array}$ & 50 \\
\hline
\end{tabular}

Figure 8 Forest plot of hypotension.

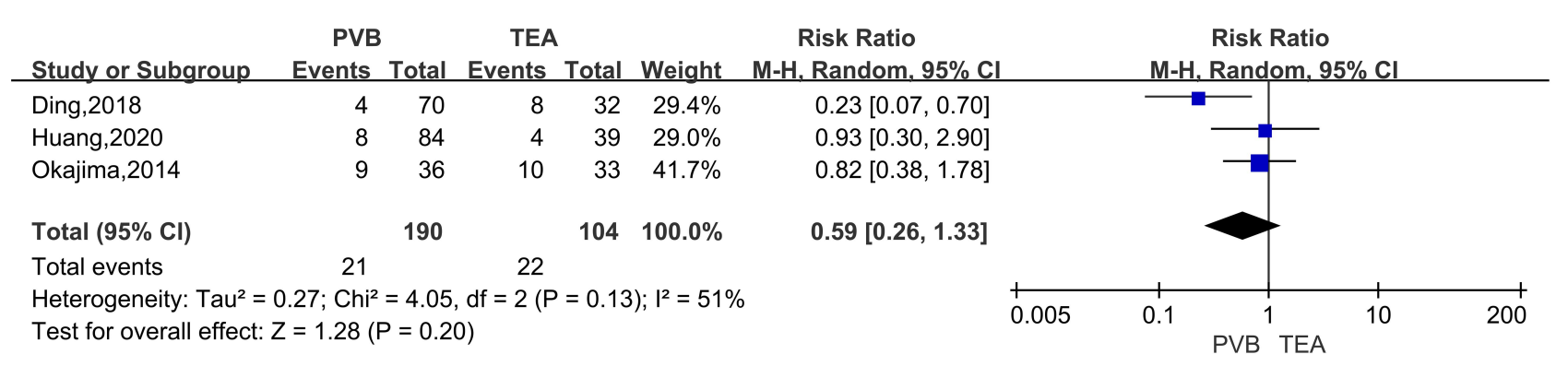

Figure 9 Forest plot of PONV.

surgery. We are the first study to compare the efficacy of TPVB and TEA after VATS. Our study provides a reference for anesthesiologists in making this decision.

TPVB appears promising. To fully understand the therapeutic effect of TPVB after thoracoscopic surgery, we suggest that future randomized controlled trials be designed according to the following standards: a) comparison of single-injection TPVB with continuous TPVB; b) comparison of TPVB with other regional anesthesia techniques such as TEA, erector spinae plane block, or intercostal nerve block; c) measurements of pain scores and recording of analgesic drug requirements within 48 hours postoperatively; d) strict monitoring of adverse reactions and complications associated with the block.

This overview also has some limitations. Despite extensive searches of three databases, we were able to identify only five RCTs for inclusion in this meta-analysis. We assume that sources of heterogeneity exist in our study, such as differences in the specific surgical methods; differences in block effects due to differences in anesthesiologist experience; differences in drug types, dosages, and concentrations; the lack of ultrasound data in the study by the Sylweriusz group; ${ }^{16}$ or recording of the postoperative pain score only in the resting state by Okajima et al Sensitivity analysis showed that the pain score in the resting state was not stable at 24 and 48 hours after surgery. Because we only included studies in English, selection bias may exist.

\section{Conclusion}

Compared with TPVB, TEA provides statistically significant but clinically unimportant short-term benefits following thoracoscopic surgery. Both TEA and TPVB can be used as options for thoracoscopic postoperative analgesia, and TPVB is more suitable for patients with coagulation dysfunction, spinal deformity, infection, or inability to accept TEA, especially for patients with high risk of hypotension.

\section{Funding}

The study was not funded.

\section{Disclosure}

The authors report no conflicts of interest for this work.

\section{References}

1. Elmore B, Nguyen V, Blank R, et al. Pain management following thoracic surgery. Thorac Surg Clin. 2015;25(4):393-409. doi:10.1016/j.thorsurg.2015.07.005

2. Bayman EO, Brennan TJ. Incidence and severity of chronic pain at 3 and 6 months after thoracotomy: meta-analysis. J Pain. 2014;15 (9):887-897. doi:10.1016/j.jpain.2014.06.005

3. Chou R, Gordon DB, de Leon-casasola OA, et al. Management of postoperative pain: a clinical practice guideline from the American Pain Society, the American Society of Regional Anesthesia and Pain Medicine, and the American Society of Anesthesiologists' committee on regional anesthesia, executive committee, and administrative council. J Pain. 2016;17(2):131-157. doi:10.1016/j. jpain.2015.12.008 
4. Bendixen M, Jørgensen OD, Kronborg C, et al. Postoperative pain and quality of life after lobectomy via video-assisted thoracoscopic surgery or anterolateral thoracotomy for early stage lung cancer: a randomised controlled trial. Lancet Oncol. 2016;17(6):836-844. doi:10.1016/S1470-2045(16)00173-X

5. Ochroch EA, Gottschalk A. Impact of acute pain and its management for thoracic surgical patients. Thorac Surg Clin. 2005;15(1):105-121. doi:10.1016/j.thorsurg.2004.08.004

6. Cook TM, Counsell D, Wildsmith JA. Royal College of Anaesthetists third national audit p: major complications of central neuraxial block: report on the third national audit project of the Royal College of Anaesthetists. $\mathrm{Br}$ J Anaesth. 2009;102(2):179-190. doi:10.1093/bja/aen360

7. D'Ercole F, Arora H, Kumar PA. Paravertebral block for thoracic surgery. J Cardiothorac Vasc Anesth. 2018;32(2):915-927. doi:10.1053/j.jvca.2017.10.003

8. Richardson J, Lönnqvist PA. Thoracic paravertebral block. $\mathrm{Br}$ $J$ Anaesth. 1998;81(2):230-238. doi:10.1093/bja/81.2.230

9. Baidya DK, Khanna P, Maitra S. Analgesic efficacy and safety of thoracic paravertebral and epidural analgesia for thoracic surgery: a systematic review and meta-analysis. Interact Cardiovasc Thorac Surg. 2014;18(5):626-635. doi:10.1093/icvts/ivt551

10. Drevon D, Fursa SR, Malcolm AL. Intercoder reliability and validity of WebPlotDigitizer in extracting graphed data. Behav Modif. 2017;41(2):323-339. doi:10.1177/0145445516673998

11. McCormick F, Cvetanovich GL, Kim JM, et al. An assessment of the quality of rotator cuff randomized controlled trials: utilizing the Jadad score and CONSORT criteria. J Shoulder Elbow Surg. 2013;22 (9):1180-1185. doi:10.1016/j.jse.2013.01.017

12. Wan X, Wang W, Liu J, et al. Estimating the sample mean and standard deviation from the sample size, median, range and/or interquartile range. BMC Med Res Methodol. 2014;135:14. doi:10.1186/ 1471-2288-14-135

13. Luo D, Wan X, Liu J, Tong T. Optimally estimating the sample mean from the sample size, median, mid-range, and/or mid-quartile range. Stat Methods Med Res. 2018;27(6):1785-1805. doi:10.1177/ 0962280216669183

14. Yeap YL, Wolfe JW, Backfish-White KM, et al. Randomized prospective study evaluating single-injection paravertebral block, paravertebral catheter, and thoracic epidural catheter for postoperative regional analgesia after video-assisted thoracoscopic surgery. J Cardiothorac Vasc Anesth. 2020;34 (7):1870-1876. doi:10.1053/j.jvca.2020.01.036

15. Ding W, Chen Y, Li D, et al. Investigation of single-dose thoracic paravertebral analgesia for postoperative pain control after thoracoscopic lobectomy - a randomized controlled trial. Int J Surg. 2018;57:8-14. doi:10.1016/j.ijsu.2018.07.006

16. Sylweriusz K, Edward F, Michal W, et al. Comparison of continuous epidural block and continuous paravertebral block in postoperative analgaesia after video-assisted thoracoscopic surgery lobectomy: a randomised, non-inferiority trial. Anaesthesiol Intensive Ther. 2016;48(5):280-287. doi:10.5603/AIT.2016.0059
17. Huang QW, Li JB, Huang Y, et al. A comparison of analgesia after a thoracoscopic lung cancer operation with a sustained epidural block and a sustained paravertebral block: a randomized controlled study. Adv Ther. 2020;37(9):4000-4014. doi:10.1007/s12325-020-01446-3

18. Okajima H, Tanaka O, Ushio $\mathrm{M}$, et al. Ultrasound-guided continuous thoracic paravertebral block provides comparable analgesia and fewer episodes of hypotension than continuous epidural block after lung surgery. J Anesth. 2015;29(3):373-378. doi:10.1007/s00540-014-1947-y

19. Cepeda MS, Africano JM, Polo R, et al. What decline in pain intensity is meaningful to patients with acute pain? Pain. 2003;105 (1-2):151-157. doi:10.1016/s0304-3959(03)00176-3

20. Bouman EAC, Sieben JM, Balthasar AJR, et al. Boundaries of the thoracic paravertebral space: potential risks and benefits of the thoracic paravertebral block from an anatomical perspective. Surg Radiol Anat. 2017;39(10):1117-1125. doi:10.1007/s00276-017-1857-4

21. Ben-David B, Merman R, Maitra S. Paravertebral blocks in thoracoscopy: single no, continuous yes. Anesthesiology. 2007;106 (2):398-399. doi:10.1097/00000542-200702000-00030

22. Hill S, Keller R, Stafford-Smith M, et al. Efficacy of single-dose, multilevel paravertebral nerve blockade for analgesia after thoracoscopic procedures. Anesthesiology. 2006;104(5):1047-1053. doi:10.1097/00000542-200605000-00022

23. Termpornlert S, Sakura S, Aoyama Y, et al. Distribution of injectate administered through a catheter inserted by three different approaches to ultrasound-guided thoracic paravertebral block: a prospective observational study. Reg Anesth Pain Med. 2020;45(11):866-871. doi:10.1136/rapm-2020-101545

24. Coppes OJM, Yong RJ, Kaye AD, et al. Patient and surgery-related predictors of acute postoperative pain. Curr Pain Headache Rep. 2020;24(4):12. doi:10.1007/s11916-020-0844-3

25. Luyet C, Siegenthaler A, Szucs-Farkas Z, et al. The location of paravertebral catheters placed using the landmark technique. Anaesthesia. 2012;67 (12):1321-1326. doi:10.1111/j.1365-2044.2012.07234.x

26. Steinthorsdottir KJ, Wildgaard L, Hansen HJ, et al. Regional analgesia for video-assisted thoracic surgery: a systematic review. Eur J Cardiothorac Surg. 2014;45(6):959-966. doi:10.1093/ejcts/ezt525

27. Hu Z, Liu D, Wang ZZ, et al. The efficacy of thoracic paravertebral block for thoracoscopic surgery: a meta-analysis of randomized controlled trials. Medicine. 2018;97(51):e13771. doi:10.1097/ MD.0000000000013771

28. Yeung JHY, Gates S, Naidu BV, et al. Paravertebral block versus thoracic epidural for patients undergoing thoracotomy. Cochrane Database Syst Rev. 2016;2(2):CD009121. doi:10.1002/14651858. CD009121.pub2
Journal of Pain Research

\section{Publish your work in this journal}

The Journal of Pain Research is an international, peer reviewed, open access, online journal that welcomes laboratory and clinical findings in the fields of pain research and the prevention and management of pain. Original research, reviews, symposium reports, hypothesis formation and commentaries are all considered for publication. The manuscript

Submit your manuscript here: https://www.dovepress.com/journal-of-pain-research-journal management system is completely online and includes a very quick and fair peer-review system, which is all easy to use. Visit http:// www.dovepress.com/testimonials.php to read real quotes from published authors. 